\title{
Epidemiology and management of oesophageal coin impaction in children
}

\author{
Matthew B. McNeill, BA ${ }^{1}$, Sarah L. W. Sperry, BA ${ }^{1,2}$, Seth D. Crockett, MD MPH ${ }^{1,2}$, C. Brock \\ Miller, MD ${ }^{1}$, Nicholas J. Shaheen, MD MPH ${ }^{1,2}$, and Evan S. Dellon, MD MPH ${ }^{1,2}$ \\ ${ }^{1}$ Center for Esophageal Diseases and Swallowing, Division of Gastroenterology and Hepatology, \\ Department of Medicine, University of North Carolina School of Medicine, Chapel Hill, NC \\ ${ }^{2}$ Center for Gastrointestinal Biology and Disease, Division of Gastroenterology and Hepatology, \\ Department of Medicine, University of North Carolina School of Medicine, Chapel Hill, NC
}

\begin{abstract}
Objective-The epidemiology of oesophageal coin impaction in children is poorly understood. We aimed to assess characteristics of patients with coin impaction and identify predictors of type of coin impacted and management strategies.
\end{abstract}

Methods-Cases of coin impaction from 2002-2009 were identified by querying a tertiary care center's billing, clinical, and endoscopy databases for the International Classification of Diseases, $9^{\text {th }}$ Revision code " 935.1 - foreign body in the oesophagus." Charts were reviewed to confirm case status and to extract pertinent data.

Results-Of 113 patients with oesophageal coin impaction (55\% male; 45\% Caucasian; mean age 2.9 years), $65(58 \%)$ swallowed a penny, $85(80 \%)$ had the impaction in the proximal oesophagus, and $103(91 \%)$ required a procedure. Thirty five (34\%) patients had an upper endoscopy performed by a gastroenterologist and $68(66 \%)$ had a laryngoscopy or oesophagoscopy performed by an otolaryngologist. Only 2 minor complications were noted. There was no significant relationship between the coin type and location of impaction, but $99 \%$ of cases performed by otolaryngologists were for proximally impacted coins, compared to $49 \%$ for gastroenterologists $(\mathrm{p}<0.001)$.

Conclusions-Oesophageal coin impaction disproportionately affected young children and extraction was frequently required. While pennies were the most commonly impacted coin, there were no clear predictors on impaction based on coin type.

\footnotetext{
(C) 2012 Editrice Gastroenterologica Italiana S.r.l. Published by Elsevier Ltd. All rights reserved. 27599-7080, Phone: (919) 966-2513, Fax: (919) 843-2508, edellon@ med.unc.edu. discovered which could affect the content, and all legal disclaimers that apply to the journal pertain.

Author contributions (all authors approved the final draft):

McNeill: Data acquisition; analysis; interpretation; manuscript drafting/revision

Sperry: Study concept; data acquisition; analysis; interpretation; manuscript drafting/revision

Crockett: Data acquisition; critical revision

Miller: Data acquisition; critical revision

Shaheen: Study concept; interpretation; critical revision

Dellon: Study concept and design; analysis; interpretation; manuscript drafting/revision
}

Corresponding Author: Evan S. Dellon MD, CB\#7080, Bioinformatics Building, 130 Mason Farm Rd., UNC-CH, Chapel Hill, NC

Publisher's Disclaimer: This is a PDF file of an unedited manuscript that has been accepted for publication. As a service to our customers we are providing this early version of the manuscript. The manuscript will undergo copyediting, typesetting, and review of the resulting proof before it is published in its final citable form. Please note that during the production process errors may be 


\section{Keywords}

oesophageal foreign bodies; coin impaction; children; endoscopy

\section{Introduction}

Oesophageal foreign body impaction (OFBI) is an emergent condition that presents with acute dysphagia, chest pain, and foreign body sensation [1]. If left untreated, OFBI can result in local oesophageal injury such as oesophagitis or ulceration, bowel obstruction from downstream migration of previously impacted items, and even oesophageal perforation or rupture (Boerhaave's syndrome) [1-4]. Young children may be particularly vulnerable to OFBI due to a small oesophagus diameter coupled with the tendency to put a variety of objects directly into their mouth.

Several studies have examined the epidemiology and characteristics of oesophageal foreign body impaction and treatments in children [5-7]. yet few have focused exclusively on coin impaction $[8,9]$. While food impactions have been reported across the age spectrum $[1,3$, 10], oesophageal coin impactions (OCI) almost exclusively affect children and are GI emergencies [11-13]. The cylindrical shape and metal composition of coins are a hazardous combination for the smaller lumen of a pediatric oesophagus.

Little is known about the epidemiology of coin impactions in children. The purpose of this study was to assess characteristics of oesophageal coin impactions in children presenting to a tertiary care center and identify predictors of type of coin impacted and management strategies.

\section{Materials and Methods}

We conducted a retrospective study of all patients presenting with OCI at University of North Carolina (UNC) Hospitals from June 2002 through December 2009. To optimize the sensitivity of our case-finding strategy, potential cases of OCI were identified by querying three separate electronic databases for all records with the International Classification of Diseases, $9^{\text {th }}$ Revision, Clinical Modification (ICD-9-CM) code "935.1-foreign body in the oesophagus." The three sources were: 1) the UNC Hospital billing database (available 20022009); 2) the UNC comprehensive clinical data warehouse (available 2006-2009); and 3) the UNC endoscopy database (available 2002-2009; Provation MD, Wolters Kluwer, Minneapolis, MN).

Charts coded for esophageal foreign bodies were then reviewed to confirm OCI status. An acute coin impaction was defined as: ingestion of coin; presentation with symptoms of oesophageal coin impaction (e.g. acute dysphagia, chest pain, foreign body sensation, inability to control secretions); and either a procedure (i.e. upper endoscopy or rigid oesophagoscopy) which demonstrated coin impaction, witnessed resolution of the impaction prior to undergoing a procedure (i.e. vomiting), or passage of the coin into the stomach or intestine as demonstrated by radiography. Patients were excluded if the ICD-9-CM code 935.1 could not be linked to an acute care visit or a procedure with the features above.

Pertinent data from first-time OCI cases were extracted and included: date and time of OCI, age, gender, race, coin type, impaction location, procedure(s) performed, procedure complications (unsuccessful extraction, respiratory compromise, cardiac arrhythmia, hypotension, mucosal injury, perforation, death), endoscopic or surgical techniques used to clear the impacted coin, oesophageal biopsy procurement (if performed), oesophageal 
dilation (if performed), other gastrointestinal comorbidities or underlying etiologies, and prior or subsequent episodes of OCI. Coin location within the oesophagus was defined based on radiology, procedure, and emergency department reports. The coin location was categorized as either in the oesophagus, above the oesophagus (level of the upper oesophageal sphincter (UOS) or above), or below the oesophagus (below the level of the lower oesophageal sphincter (LOS)). For coins in the oesophagus, the location was subdivided into proximal and distal oesophagus). Patients with more than one occurrence of OCI during this time period, either at our institution or reported by history, were categorized as having recurrent $\mathrm{OCI}$. When present, cases of eosinophilic oesophagitis (EoO) were defined per 2007 consensus guidelines [14].

Descriptive statistics were used to summarize the findings. For bivariate analysis, means were compared with t-test and proportions were compared with chi-square. For variables where there were not normal distributions, medians were compared using the Wilcoxon Rank-sum test. All statistical analyses were performed using STATA, version 10.1 (College Station, TX, USA). This study was approved by the UNC Institutional Review Board.

\section{Results}

\section{Patient Characteristics}

Overall, 113 patients with OCI were identified from our search (Table 1). This represented $21 \%$ of all patients with OFBI at our center over the study time frame, and $52 \%$ of children presenting with OFBI. Subjects with OCI were 55\% male, $45 \%$ Caucasian and ranged in age from 3 months to 10 years, with a mean age of 2.9 years and OCI most commonly occurring in the youngest of patients (Figure 1). Underlying gastrointestinal comorbidities contributing to the episode of OCI were present in only three subjects: one with an oesophageal stricture, one with a previous tracheo-oesophageal fistula repair, and one with EoO.

The coin ingestion was witnessed in 25 (28\%) cases, and coins were most commonly ingested during the evening or night-time hours, with subsequent presentation to the emergency department (Table 2). The most commonly impacted coin was a penny, occurring in 65 cases (58\%). Quarters were impacted in 18 cases (16\%), while dimes and nickels were found in 10 cases each (9\%). Multiple coins were impacted in six cases (5\%).

There was no significant relationship between coin type and patient race or gender, however we did observe a significant relationship between coin type and age with quarters becoming impacted in older children (mean age 6 years) compared to the other coin types $(\mathrm{p}<0.0001)$.

Of patients who presented with OCI, 105 (95\%) had their coin persistently impacted within the oesophagus. The remaining cases expelled the coin via coughing, passed the coin to the lower GI tract prior to further intervention, or had an impacted coin above the upper oesophageal sphincter (Table 2). Of coins impacted in the oesophagus, $85(80 \%)$ were located in the proximal (thoracic) oesophagus, but there was no significant relationship between the coin type and location of impaction within the oesophagus.

\section{Procedure Characteristics}

A total of 103 (91\%) patients underwent a procedure to treat their OCI (Table 3); no information was available for the other two patients with a persistent coin impaction. Sixtyeight $(66 \%)$ procedures were laryngoscopy/oesophagoscopy performed by colleagues in otolaryngology, and the remaining 35 (34\%) were endoscopies performed by the GI or surgical service. Coin extraction was the intended goal of all of the procedures and involved the use of forceps, coin graspers, nets, and snares. One patient underwent oesophageal dilation for treatment of an oesophageal stricture. An oesophageal biopsy was only performed in one patient, and this patient was subsequently diagnosed with EoO. Two 
patients $(2 \%)$ experienced a complication during their procedure, including a mucosal abrasion (1) and bronchospasm (1). The patient with the mucosal abrasion was discharged in stable condition. The patient who experienced bronchospasm was intubated and admitted for two days for observation before a discharge in stable condition.

\section{Relationships between $\mathrm{OCl}$ and the procedure setting}

When comparing procedures performed by gastroenterologists and procedures performed by otolaryngologists, we observed several significant associations (Table 4). Patients treated by the GI service were older (3.6 yrs vs. $2.4 \mathrm{yrs}, \mathrm{p}=0.005$ ) and arrived at the emergency department earlier in the day (mean time of 9:37 a.m. vs. 1:35 p.m., $\mathrm{p}=0.02$ ) compared to those treated by the otolaryngology service. Although there was no association between coin type and procedure type, there was a significant difference between coin location within the oesophagus and procedure type. Specifically, coins were impacted proximally in $49 \%$ of cases performed by gastroenterologists, compared to $99 \%$ of cases performed by otolaryngologists $(\mathrm{p}<0.001)$. Members of both specialties were successfully and safely able to extract proximally impacted coins.

\section{Discussion}

Pediatric oesophageal coin impaction is a GI emergency which typically requires an invasive procedure to extract the coin. Numerous studies have examined foreign body impaction, but most have focused on adults and food impaction, likely owing to the fact that the incidence of food impaction in adults is much greater than coin impaction [11, 15]. Relative to adults, children have a much higher incidence of coin impaction, and coin impactions constitute the largest proportion of all pediatric foreign body impactions [11, 13, $16,17]$. Presumably, this is due to the ubiquitousness of coins and the oral fixation associated with normal development in young children. Few pediatric studies have limited their research to coins, despite it being the most commonly impacted foreign body in children [8]. The purpose of this study was to more closely characterize the epidemiology and treatment associated with pediatric oesophageal coin impaction at a tertiary medical center.

Our finding that three-quarters of the patients with OCI were below the age of four makes intuitive sense. This is the age when children are becoming more mobile and independent from their parents, as well as developing their gross and fine motor skills, including a fullydeveloped pincer grasp around 12 months [18]. Interestingly, very few children had a clear underlying oesophageal disease as the etiology of the OCI. This suggests that anatomic issues related to growth and the development of the oesophagus predominate, but this study was retrospective and it is possible that structural lesions could have been missed. We would similarly caution that only one patient in this study had oesophageal biopsies at the time of coin impaction, and that patient was diagnosed with EoO. It is possible that EoO is more prevalent in children with coin impactions, as it is in adults with food impactions $[15,19$, 20], but without a prospective study obtaining oesophageal biopsies in all patients, this remains only a hypothesis.

Is there any explanation for type of coin that becomes impacted? The impacted coin distribution in this study roughly mirrored the 2010 US Mint coin production in some ways, with pennies being the most impacted (64\% of impacted coins, $67 \%$ of produced coins) [21]. Although dimes were the second most produced coin (18.75\%), they only made up $10 \%$ of impacted coins. Quarters, making up 15\% of impacted coins, were more prevalent than their production might suggest (5.8\% of produced coins). The higher rate of quarter impaction could be due to its larger size $(24.26 \mathrm{~mm})$ (Figure 2). Likewise, the smaller size of dimes $(17.91 \mathrm{~mm})$ may decrease the propensity for impaction, but even an object $18 \mathrm{~mm}$ in 
diameter can become lodged in an infant's oesophagus. Despite the range in coin types and sizes that we observed, there were no strong associations between the coin type and most clinical factors. However, we did find that quarters were more commonly impacted in older children. It is possible this is because quarters are too large to be swallowed or to pass the UES in very young children, or conversely because smaller coins may be less likely to become impacted in the larger-caliber oesophagus of an older child.

Nearly all children with an OCI required an invasive procedure for coin extraction. As would be expected, the otolaryngology service was involved for coins felt to be impacted at the UOS or in the proximal oesophagus, and this tendency was independent of coin type. This difference likely was due to concerns about airway control and coin retrieval in close proximity to the trachea, and may be the preferred approach in proximally impacted coins in children. However, both GI and otolaryngology physicians were safely able to extract proximally impacted coins. At our institution, coin extraction is an urgently performed procedure, but the exact timing in children can depend on the availability of anesthesia support. When patients present to the emergency department with symptoms of OCI, a chest radiograph is obtained to confirm that a coin is impacted. If the coin is at the level of the UOS or higher, the otolaryngology service is often contacted to perform the procedure, but the gastroenterology service is frequently consulted as well.

This study has several strengths that contribute to the validity of our findings. This is one of the largest studies conducted specifically examining children who have swallowed coins. We performed a thorough review of multiple electronic resources during the study time frame in order to capture all episodes of OCI seen at our institution. As such, we have a large sample with the ability to describe the epidemiology and analyze predictors. However, we acknowledge that the retrospective and single-center design of this study is a limitation and may impact generalizability, and the conclusions must be interpreted in that context. Further prospective research could attempt to determine more definitively whether the cause of coin impaction in children is simply anatomic (i.e. a small-caliber oesophagus or an anatomic narrowing at the level of the aortic arch) or represents underlying pathology such as unrecognized eosinophilic oesophagitis.

In conclusion, oesophageal coin impaction disproportionately impacts young children and the large majority will require an invasive and costly procedure to extract the coin. While pennies were the most commonly impacted coin, perhaps because they are small, shiny, and visually appealing, all coin types were represented in our study population. While coin extraction was safe in general, our data can help parents and pediatricians appreciate the hazardous nature of coins as infants and toddlers develop motor skills and begin to put objects in their mouths. Coins should never be considered an appropriate toy or teething device, even when they have a large diameter.

\section{Acknowledgments}

Grant support: This work was supported by a grant from the Doris Duke Charitable Foundation to the University of North Carolina-Chapel Hill (SLWS), NIH training grant T32DK007634 (SDC), NIH award number KL2RR025746 from the National Center for Research Resources (ESD) and a Junior Faculty Development Award from the American College of Gastroenterology (ESD).

\section{Abbreviations \\ OCI oesophageal coin impaction \\ ED emergency department}




$\begin{array}{ll}\text { OFBI } & \text { oesophageal foreign body impaction } \\ \text { OGD } & \text { oesophagogastroduodenoscopy } \\ \text { EoO } & \text { eosinophilic oesophagitis } \\ \text { ICD-9-CM } & \text { International Classification of Diseases, } 9^{\text {th }} \text { Revision, Clinical Modification } \\ \text { UNC } & \text { University of North Carolina }\end{array}$

\section{References}

1. Longstreth GF, Longstreth KJ, Yao JF. Esophageal food impaction: epidemiology and therapy. A retrospective, observational study. Gastrointest Endosc. 2001; 53:193-198. [PubMed: 11174291]

2. Craik JD, Laffer CH, Newton A. Boerhaave's syndrome: a pain in the neck. Emerg Med J. 2009; 26:461-462. [PubMed: 19465631]

3. Vicari JJ, Johanson JF, Frakes JT. Outcomes of acute esophageal food impaction: success of the push technique. Gastrointest Endosc. 2001; 53:178-181. [PubMed: 11174288]

4. Weinstock LB, Shatz BA, Thyssen SE. Esophageal food bolus obstruction: evaluation of extraction and modified push techniques in 75 cases. Endoscopy. 1999; 31:421-425. [PubMed: 10494678]

5. Lao J, Bostwick HE, Berezin S, et al. Esophageal food impaction in children. Pediatr Emerg Care. 2003; 19:402-407. [PubMed: 14676489]

6. Hurtado CW, Furuta GT, Kramer RE. Etiology of esophageal food impactions in children. J Pediatr Gastroenterol Nutr. 2011; 52:43-46. [PubMed: 20975581]

7. Miller RS, Willging JP, Rutter MJ, et al. Chronic esophageal foreign bodies in pediatric patients: a retrospective review. Int J Pediatr Otorhinolaryngol. 2004; 68:265-272. [PubMed: 15129936]

8. Tander B, Yazici M, Rizalar R, et al. Coin ingestion in children: which size is more risky? J Laparoendosc Adv Surg Tech A. 2009; 19:241-243. [PubMed: 19215216]

9. Waltzman ML, Baskin M, Wypij D, et al. A randomized clinical trial of the management of esophageal coins in children. Pediatrics. 2005; 116:614-619. [PubMed: 16140701]

10. Byrne KR, Panagiotakis PH, Hilden K, et al. Retrospective analysis of esophageal food impaction: differences in etiology by age and gender. Dig Dis Sci. 2007; 52:717-721. [PubMed: 17253139]

11. Nadir A, Sahin E, Nadir I, et al. Esophageal foreign bodies: 177 cases. Dis Esophagus. 2011; 24:69. [PubMed: 20626451]

12. Wu WT, Chiu CT, Kuo CJ, et al. Endoscopic management of suspected esophageal foreign body in adults. Dis Esophagus. 2010

13. Miyazaki T, Hokama N, Kubo N, et al. Management of esophageal foreign bodies: experience of 90 cases. Esophagus. 2009; 6:155-159.

14. Furuta GT, Liacouras CA, Collins MH, et al. Eosinophilic Esophagitis in Children and Adults: A Systematic Review and Consensus Recommendations for Diagnosis and Treatment. Sponsored by the American Gastroenterological Association (AGA) Institute and North American Society of Pediatric Gastroenterology, Hepatology, and Nutrition. Gastroenterology. 2007; 133(4):13421363. [PubMed: 17919504]

15. Sperry SLW, Crockett SD, Miller CB, et al. Esophageal foreign body impactions: Epidemiology, time trends, and the impact of the increasing prevalence of eosinophilic esophagitis.

16. Harned RK 2nd, Strain JD, Hay TC, et al. Esophageal foreign bodies: safety and efficacy of Foley catheter extraction of coins. AJR Am J Roentgenol. 1997; 168:443-446. [PubMed: 9016224]

17. Arana A, Hauser B, Hachimi-Idrissi S, et al. Management of ingested foreign bodies in childhood and review of the literature. Eur J Pediatr. 2001; 160:468-472. [PubMed: 11548183]

18. Johnson CP, Blasco PA. Infant growth and development. Pediatr Rev. 1997; 18:224-242. [PubMed: 9203831]

19. Desai Tk Fau - Stecevic V, Stecevic V Fau - Chang C-H, Chang Ch Fau - Goldstein NS, et al. Association of eosinophilic inflammation with esophageal food impaction in adults. 
20. Kerlin P, Jones D, Remedios M, et al. Prevalence of eosinophilic esophagitis in adults with food bolus obstruction of the esophagus. J Clin Gastroenterol. 2007; 41:356-361. [PubMed: 17413601] 21. www.USMint.gov. [cited; Available from: 


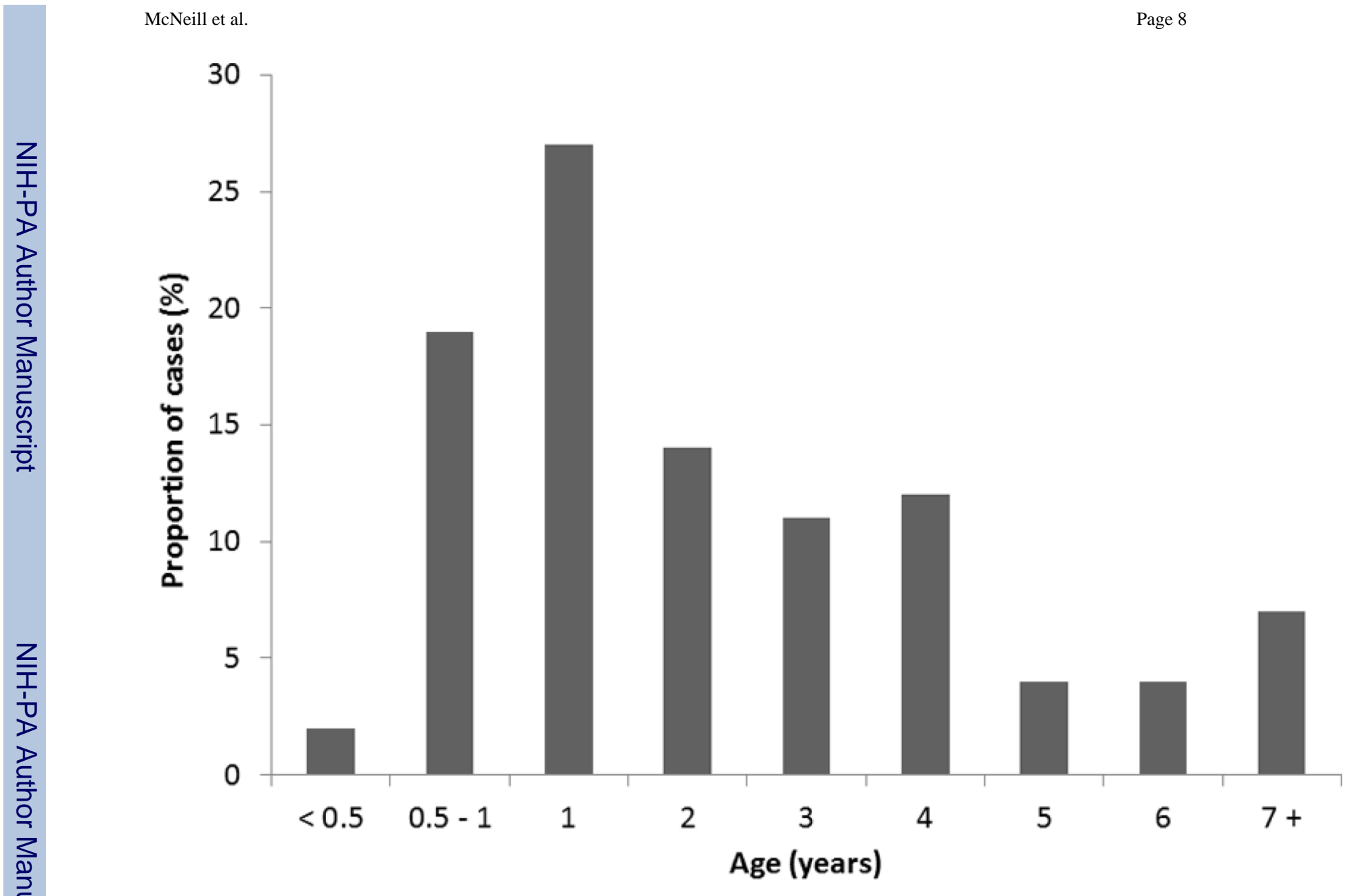

Figure 1.

Age at presentation of oesophageal coin impaction 


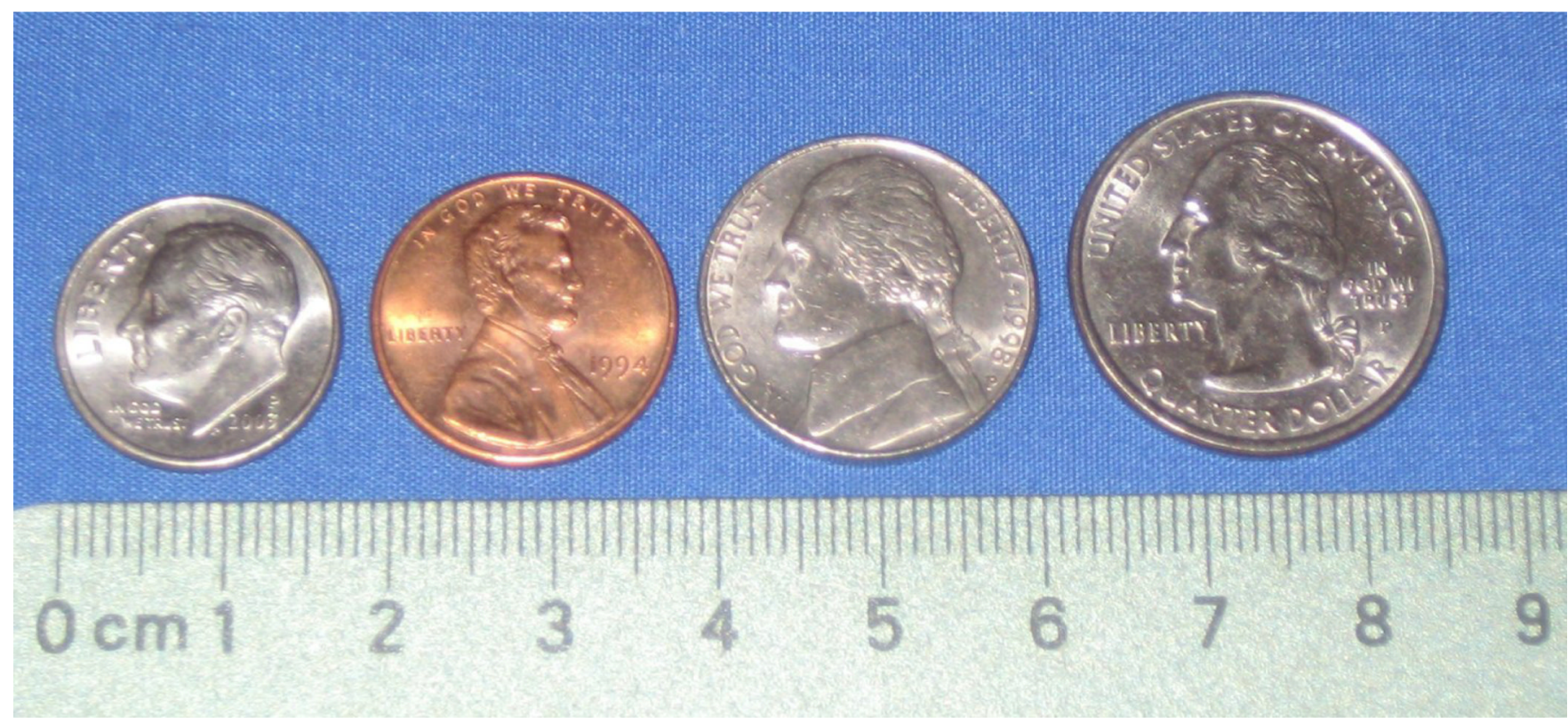

Figure 2.

United States coins by size. Standard U.S. Mint coin diameters are $17.91 \mathrm{~mm}$ for a dime, $19.05 \mathrm{~mm}$ for a penny, $21.21 \mathrm{~mm}$ for a nickel, and $24.26 \mathrm{~mm}$ for a quarter. 


\section{Table 1}

Patient demographics, $\mathrm{N}=113$

\begin{tabular}{lc}
\hline Characteristic & Number (\%) \\
\hline Gender & $51(45)$ \\
Female & $62(55)$ \\
Male & \\
\hline Age (years) & $2.9( \pm 2.2)$ \\
Mean (standard devitiation) & \\
\hline Race & $51(45)$ \\
Caucasian & $34(30)$ \\
Black & $11(10)$ \\
Hispanic & $1(1)$ \\
Asian & $2(2)$ \\
Native American & $14(12)$ \\
Other & 1 \\
\hline Underlying GI pathology & 1 \\
Stricture & $110(97)$ \\
Previous TEF repair & \\
Eosinophilic oesophagitis & \\
None & 1 \\
\hline
\end{tabular}

Dig Liver Dis. Author manuscript; available in PMC 2013 June 01. 
Table 2

Visit characteristics for patients presenting with coin impaction

\begin{tabular}{|c|c|}
\hline & Number $(\%)$ \\
\hline \multicolumn{2}{|l|}{ Coin ingestion witnessed? } \\
\hline Witnessed & $25(28)$ \\
\hline Unwitnessed & $64(72)$ \\
\hline Unspecified & 24 \\
\hline \multicolumn{2}{|l|}{ Coin type by impaction } \\
\hline Penny & $65(58)$ \\
\hline Nickel & $10(9)$ \\
\hline Dime & $10(9)$ \\
\hline Quarter & $18(16)$ \\
\hline Unspecified & $4(4)$ \\
\hline Multiple coins $*$ & $6(5)$ \\
\hline \multicolumn{2}{|l|}{ Coin type total } \\
\hline Penny & $76(64)$ \\
\hline Nickel & $12(10)$ \\
\hline Dime & $12(10)$ \\
\hline Quarter & $18(15)$ \\
\hline \multicolumn{2}{|l|}{ Coin Location Relative to Oesophagus } \\
\hline In oesophagus & $105(95)$ \\
\hline Pre-oesophagus (UOS or above) & $1(1)$ \\
\hline Post-oesophagus (Below LOS or passed) & $5(5)$ \\
\hline NA & 2 \\
\hline \multicolumn{2}{|l|}{ Coin Location within Oesophagus } \\
\hline Thoracic (proximal) & $85(80)$ \\
\hline Lower (distal) & $20(19)$ \\
\hline UOS & $1(1)$ \\
\hline NA & 7 \\
\hline \multicolumn{2}{|l|}{ Time of Ingestion } \\
\hline $12 \mathrm{am}-4 \mathrm{am}$ & $2(5)$ \\
\hline$>4 \mathrm{am}-8 \mathrm{am}$ & $1(2)$ \\
\hline$>8 \mathrm{am}-12 \mathrm{pm}$ & $8(18)$ \\
\hline$>12 \mathrm{pm}-4 \mathrm{pm}$ & $5(11)$ \\
\hline$>4 \mathrm{pm}-8 \mathrm{pm}$ & $15(34)$ \\
\hline$>8 \mathrm{pm}-12 \mathrm{am}$ & $13(30)$ \\
\hline Unknown & 69 \\
\hline \multicolumn{2}{|l|}{ Time of ED arrival } \\
\hline $12 \mathrm{am}-4 \mathrm{am}$ & $19(21)$ \\
\hline
\end{tabular}

Dig Liver Dis. Author manuscript; available in PMC 2013 June 01. 


\begin{tabular}{|c|c|}
\hline & Number $(\%)$ \\
\hline$>4 \mathrm{am}-8 \mathrm{am}$ & $9(10)$ \\
\hline$>8 \mathrm{am}-12 \mathrm{pm}$ & $9(10)$ \\
\hline$>12 \mathrm{pm}-4 \mathrm{pm}$ & $16(17)$ \\
\hline$>4 \mathrm{pm}-8 \mathrm{pm}$ & $20(22)$ \\
\hline$>8 \mathrm{pm}-12 \mathrm{am}$ & $19(21)$ \\
\hline NA & 21 \\
\hline \multicolumn{2}{|c|}{ Time from Ingestion to UNC ED arrival (hours) } \\
\hline Mean (SD) & $5.41( \pm 3.1)$ \\
\hline Median & 5.83 \\
\hline$<1$ & $4(10)$ \\
\hline$>1-2$ & $4(10)$ \\
\hline$>2-4$ & $5(12)$ \\
\hline$>4-6$ & $11(27)$ \\
\hline$>6-8$ & $9(22)$ \\
\hline$>8-10$ & $5(12)$ \\
\hline$>10$ & $3(7)$ \\
\hline NA & 72 \\
\hline \multicolumn{2}{|c|}{ Length of stay in ED (hours) } \\
\hline Mean (SD) & $4.5( \pm 2.3)$ \\
\hline Median & 3.9 \\
\hline \multicolumn{2}{|c|}{ Admission to hospital from ED? } \\
\hline Yes & $96(86)$ \\
\hline No & $15(14)$ \\
\hline Unspecified & 2 \\
\hline \multicolumn{2}{|c|}{ Procedure ${ }^{* *}$ performed in relation to ED visit? } \\
\hline Yes & $101(89)$ \\
\hline No & $8(7)$ \\
\hline Not specified & $4(4)$ \\
\hline \multicolumn{2}{|c|}{ Time from ED arrival to procedure (hours) } \\
\hline Mean (SD) & $12.6( \pm 9.1)$ \\
\hline Median & 11.2 \\
\hline
\end{tabular}

Abbreviations: UOS = upper oesophageal sphincter; LOS = lower oesophageal sphincter; $\mathrm{ED}=$ emergency department; UNC = University of North Carolina; $\mathrm{SD}=$ standard deviation

Multiple coins included two pennies, three pennies, two cases of two pennies and a dime, and two cases of a nickel and a penny **

procedures include upper endoscopy performed by GI, otolaryngology or surgical services; laryngoscopy/oesophagoscopy performed by otolaryngology and surgical procedures

Dig Liver Dis. Author manuscript; available in PMC 2013 June 01. 
Table 3

Procedure Characteristics

\begin{tabular}{|c|c|}
\hline & Number $(\%)$ \\
\hline \multicolumn{2}{|l|}{ Procedure } \\
\hline Yes & $103(93)$ \\
\hline No & $8(7)$ \\
\hline Not specified & 2 \\
\hline \multicolumn{2}{|l|}{ Procedure type } \\
\hline OGD (performed by GI or surgical service) & $35(34)$ \\
\hline Laryngoscopy/oesophagoscopy (performed by the otolaryngology service) & $68(66)$ \\
\hline NA & 10 \\
\hline \multicolumn{2}{|l|}{ Tools used } \\
\hline Forceps (non-biopsy) & $61(60)$ \\
\hline Roth net & $1(1)$ \\
\hline Snare & $1(1)$ \\
\hline Coin grasper & $20(20)$ \\
\hline NA & 63 \\
\hline \multicolumn{2}{|l|}{ Dilation performed? } \\
\hline Yes & $1(1)$ \\
\hline No & $102(99)$ \\
\hline NA & 10 \\
\hline \multicolumn{2}{|l|}{ Biopsies taken during OGD? } \\
\hline Yes & 1 \\
\hline No & $34(30)$ \\
\hline No OGD performed & $76(67)$ \\
\hline Not specified & 2 \\
\hline \multicolumn{2}{|l|}{ Complication * during procedure? } \\
\hline Yes & $2(2)$ \\
\hline No & $99(98)$ \\
\hline Not specified & 4 \\
\hline NA & 8 \\
\hline
\end{tabular}

Abbreviations: $\mathrm{OGD}=$ oesophagogastroduodenoscopy; $\mathrm{NA}=$ not available

* Complications included mucosal abrasion and bronchospasm 
Table 4

Relationships between OCI and procedure type

\begin{tabular}{|c|c|c|c|}
\hline & \multicolumn{3}{|c|}{ Procedure Type } \\
\hline & $\begin{array}{l}\text { Gastroenterologist } \\
\qquad(\mathbf{N}=35)\end{array}$ & $\begin{array}{c}\text { Otolaryngologist } \\
(\mathbf{N}=68)\end{array}$ & p-value ${ }^{*}$ \\
\hline \multicolumn{4}{|l|}{ Age (years) } \\
\hline Mean (SD) & $3.62( \pm 2.4)$ & $2.37( \pm 1.9)$ & 0.005 \\
\hline \multicolumn{4}{|l|}{ ED Arrival Time } \\
\hline Mean (SD in hours) & 9:37 a.m. $( \pm 8.2)$ & 1:35 p.m. $( \pm 6.6)$ & 0.02 \\
\hline \multicolumn{4}{|l|}{ Coin location $(\mathrm{n}, \%)$} \\
\hline Proximal (thoracic) & $17(49)$ & $67(99)$ & $<0.001$ \\
\hline Distal (lower) & $18(51)$ & $1(1)$ & \\
\hline \multicolumn{4}{|l|}{ Coin Type (n, \%) } \\
\hline Penny & $22(63)$ & $39(65)$ & \\
\hline Nickel & $2(6)$ & $8(13)$ & \\
\hline Dime & $5(14)$ & $5(8)$ & 0.2 \\
\hline Quarter & $6(17)$ & $8(13)$ & \\
\hline Unspecified & 0 & 2 & \\
\hline Multiple & 0 & 6 & \\
\hline
\end{tabular}

Abbreviations: $\mathrm{SD}=$ standard deviation; $\mathrm{ED}=$ emergency department

*alculated using t-test for means and chi-square for proportions 